\title{
Analisis Tata Kelola Teknologi Informasi Untuk Mendefinisikan Arsitektur Informasi Dengan Framework COBIT 4.1 (Studi Kasus Instalasi Rawat Jalan RSUD Prov. NTB)
}

\author{
(Information Technology Governance Analysis to Define Architecture Information \\ Using the COBIT Framework 4.1 Case studies Instalasi Rawat Jalan RSUD Prov. \\ NTB)
}

\author{
Media Isti Azzizah*, Nadiyasari Agitha, Ida Bagus Ketut Widiartha \\ Dept Informatics Engineering, Mataram University \\ Jl. Majapahit 62, Mataram, Lombok NTB, INDONESIA \\ Email: mediaisti.mi@gmail.com,[nadiya,widi]@unram.ac.id
}

${ }^{*}$ Penulis Korespondensi

\begin{abstract}
Treatment for outpatient installations (IRJA) NTB provincial hospitals have used hospital management information systems, but this is still not effective. The information system is not effective because registration centred in the main hall. The centralized registration caused the accumulation of patient queues that occurred in each IRJA polyclinic, and this was due to the absence of an integrated queue number between registrations carried out in the main hall and IRJA polyclinics. Therefore, the governance of information architecture processes needs to be applied to optimize information systems. We use COBIT 4.1 to conduct governance. The aim is to get existing and expected outpatients from Prov. NTB Hospital. So, it can help to manage information architecture to perform quality and competitive outpatient services. The results showed the IT processes selected in $\mathrm{PO2}$ (Determine Information Architecture) and AI4 (Activate and Use). We reach the maturity level of all IT processes at level 3 (the specified process) for conditions as they are and 5 (optimized) for conditions that will occur. The level of maturity can help the NTB Provincial Hospital to improve its services.
\end{abstract}

Key words: IT Governance, COBIT 4.1, maturity level, IT process, PO2, AI4

\section{PENDAHULUAN}

Pentingnya peran teknologi informasi dalam memudahkan kinerja suatu perusahaan menyebabkan meningkatnya perusahaan yang menggunakan tata kelola teknologi informasi (TI). Dengan adanya pengembangan tata kelola TI tersebut, maka penerapan kinerja TI dapat diarahkan dan menghasilkan pedoman yang sesuai dengan rencana strategis perusahaan.

Saat ini IRJA RSUD Prov. Nusa Tenggara Barat (NTB) menggunakan TI untuk mengaplikasikan kegiatan pelayanan di rumah sakit, salah satunya yaitu telah menerapkan Sistem Informasi Manajemen Rumah Sakit (SIMRS). Tetapi, penggunaan SIMRS tersebut belum efektif. Salah satu masalah yang ada adalah pendaftaran pelayanan pasien di IRJA masih terpusat di mainhall rumah sakit. Pendaftaran terpusat tersebut menyebabkan menumpuknya antrean pasien yang terjadi di setiap poliklinik IRJA, hal ini dikarenakan belum adanya nomor antrean yang terintegrasi antara pendaftaran yang dilakukan di mainhall dengan poliklinik IRJA. Saat ini di IRJA menggunakan modul-modul aplikasi yang ada pada SIMRS yaitu modul pendaftaran yang akan memberikan pelayanan pendaftaran pasien yang akan berobat, modul poliklinik untuk menginputkan tindakan yang ada di poli, dan modul kasir untuk melakukan pembayaran pasien. Namun, saat ini IRJA belum memiliki dokumentasi terkait petunjuk penggunaan aplikasi SIMRS, dan pada penggunaannya diberikan secara lisan oleh staf teknologi informasi di RSUD Prov. NTB.

Tata kelola TI memiliki beberapa tools yang sering digunakan, salah satunya adalah COBIT. COBIT merupakan framework yang menyediakan berbagai macam indikator untuk membantu mengoptimalkan perusahaan dalam pengelolaan teknologi informasi. COBIT juga membantu dalam mengembangkan pengendalian terhadap manajemen TI yang layak digunakan suatu organisasi.

Berdasarkan permasalahan yang ditemukan di IRJA RSUD Prov. NTB mempengaruhi proses penetapan arsitektur informasi yang tepat untuk mengoptimalkan penggunaan sistem informasi yang ada. Sehingga perlu dilakukan tata kelola agar pelayanan yang diberikan lebih baik. Pendefinisian arsitektur informasi akan didukung dengan adanya panduan modul-modul yang ada pada aplikasi SIMRS serta bahan pelatihan yang digunakan untuk membantu permasalahan belum adanya panduan penggunaan aplikasi yang digunakan dan belum dilakukannya pelatihan secara formal terhadap staf terkait penggunaan aplikasi yang digunakan di IRJA. 
Berdasarkan analisis permasalahan tersebut perlu dilakukan tata kelola dengan menggunakan proses teknologi informasi yang terpilih dari permasalahan yang terdapat pada IRJA RSUD Prov. NTB menggunakan framework COBIT 4.1. COBIT 4.1 merupakan framework yang digunakan untuk menganalisis kebutuhan TI yang dibutuhkan oleh perusahaan atau instansi [1]. Tujuannya untuk mendapatkan kondisi as-is dan kondisi to-be agar dapat membantu mengelola arsitektur informasi pada RSUD Prov. NTB sesuai dengan tujuan IRJA yaitu menjadikan pelayanan rawat jalan yang bermutu dan berdaya saing dengan mengutamakan pelayanan prima.

\section{TINJAUAN PUSTAKA DAN DASAR TEORI}

\section{A. Tinjauan Pustaka}

Penelitian pada RSUD Bari Palembang menggunakan COBIT 4.1 dalam melaksanakan analisisnya. RSUD Bari mengukur tingkat kematangan dengan menggunakan domain AI. RSUD Bari mendapatkan hasil level defined. Selain itu, terdapat satu proses pada level repeatable but intuitive proses manage changes. Pada segi monitoring dan evaluasi, RSUD Bari belum memberikan hasil yang optimal. Hal ini dikarenakan audit sistem informasi belum dilakukan secara keseluruhan [2].

Pada penelitian lainnya yang melakukan Perancangan TI untuk meningkatkan layanan Sistem Informasi Kesehatan pada Dinas Kesehatan Kabupaten Jepara, proses TI yang digunakan adalah domain Deliver and Support (DS) khususnya DS11 yaitu manajemen data dan proses kontrol yang berhubungan, yaitu PO2 (Define the Information Architecture), DS4 (Ensure Continuous Service), DS5 (Ensure Systems Security) dan DS13 (Manage Operations). Analisis yang dilakukan adalah menguji masing-masing variabel menggunakan bivariate one tailed dan analisis korelasi Kendalll's Tau serta Spearman. Kesimpulan yang didapatkan dari penelitian ini adalah bahwa terdapat empat input yang saling berhubungan dan saling terkait, yaitu PO2, DS1, DS4, dan DS5 serta satu masukan tidak saling berhubungan yaitu AI4 [3].

Framewok COBIT 4.1 juga telah membantu penelitian yang melakukan Audit Sistem Informasi Instalasi Rawat Jalan pada Rumah Sakit Umum Haji Surabaya. Dalam penelitian ini audit sistem informasi dilakukan dengan cara mengidentifikasi ruang lingkup dan tujuan audit berdasarkan balanced scorecard. Hasil dalam penelitian ini yaitu diperoleh tingkat kematangan sebesar 3,21 atau dalam proses defined. Berdasarkan analisis yang telah dilakukan, Rumah Sakit Umum Haji Surabaya perlu melakukan audit terhadap keamanan sistem [4].

Pada penelitian yang dilakukan pada RSUD Provinsi NTB yang mengkaji Infrastruktur Jaringan, masalah yang diangkat adalah jaringan yang dimiliki oleh RSUD Prov. NTB yang belum dioptimalkan. Hasil dari peneltian mendapatkan keadaan sekarang pada RSUD Prov NTB di level 3 dan akan ditingkatkan menjadi level 5. Penelitian ini menggunakan PO2 dan AI3 sebagai proses TI yang akan meningkatkan performa TI di RSUD Prov NTB.[5]
Berdasarkan beberapa penelitian terkait yang telah disebutkan sebelumnya, Framework COBIT 4.1 telah banyak digunakan untuk melakukan tata kelola TI dan dapat membantu perusahaan atau organisasi dalam memperbaiki tata kelola TI dengan baik. Maka dari itu, penulis melakukan penelitian yang akan mengarahkan IRJA RSUD Prov. NTB untuk mendapatkan rekomendasi terkait arsitektur informasi dengan menggunakan Framework COBIT 4.1.

\section{B. Dasar Teori}

\section{B.1. Tata Kelola Teknologi Informasi \& COBIT}

Tata kelola TI adalah bentuk konsekuensi para stakeholder dan melakukan pembauran antara tata kelola perusahaan atau organisasi dengan pola dasar kepemimpinan dana pa yang terjadi dalam struktur dan proses yang terjadi dalam perusahaan. Tata kelola TI bermanfaat untuk memastikan bahwa organisasi atau perusahaan tersebut kontributif terhadap strategi dan tujuan bisnis. [6].

COBIT melakukan pembauran dan penerapan dalam mengelola TI. COBIT juga menyajikan kerangka kerja untuk mengelola TI agar dapat melakukan manajemen resiko dan memperoleh manfaat yang berhubungan dengan TI [7].

\section{B.2. Balanced Scorecard}

Balanced Scorecard menggambarkan sebuah standar kinerja yang terpadu dan datang dari strategi perusahaan juga mendukung cetak biru perusahaan maupun organisasi. Tujuan dan ukuran Scorecard diambil dari visi, misi dan strategi. Kinerja perusahaan yang bagi oleh scorecard adalah pada bagian: keuangan, pelanggan, proses bisnis internal, serta pembelajaran dan pertumbuhan. [8].

\section{B.3. RACI Chart \& Inter Quartile Range (IQR)}

Responsible, accountable, consulted, informed (RACI) chart adalah bagaimana menciptakan kerangka yang menampilkan setiap orang terlibat di dalam perusahaan atau organisasi. Matriks tersebut akan membantu dalam membagi kapasitas dan responsibilitas yang baiknya dapat dipunyai oleh setiap orang dalam perusahaan [9].

Metode IQR merupakan metode yang digunakan dalam analisis statistik untuk membantu menarik kesimpulan mengenai sekumpulan data semisal data kuesioner. Pada setiap pertanyaan, pengurutan jawaban dari keseluruhan responden dilakukan dan kemudian dicari nilai kuartil 1 (Q1) dan kuartil 3 (Q3). Jawaban-jawaban yang ada di luar batas observasi tidak akan diikutkan dalam perhitungan [10]. Kelebihan metode IQR dibanding metode yang lain (Range, Standar Deviasi) yaitu nilai IQR tidak terpengaruh dengan nilai outlier (nilai yang berada di batas atas dan nilai yang berada pada batas bawah)[11].

\section{B.4. Uji Realibilitas dan Validitas}

Uji realibilitas ditentukan dengan menggunakan metode Cronbach's Alpha[11]. Pengujian ini dilakukan 
untuk menentukan konsistensi responden dalam menjawab kuesioner. Data yang dianalisa bersifat reliabel jika memiliki koefisien Cronbach's Alpha di atas 0,60.[12]

Uji validitas digunakan untuk mengukur jawaban yang telah dijawab responden bersifat valid atau tidak. Uji validitas menggunakan metode korelasi Pearson. Metode ini merupakan alat uji statistik untuk menguji dua buah variabel yang nantinya akan ditentukan berskala interval atau rasio.[13]

\section{Metode PENELITIAN}

Flowchart atau diagram alir dari tahapan penelitian ini dapat dilihat pada Gambar 1.

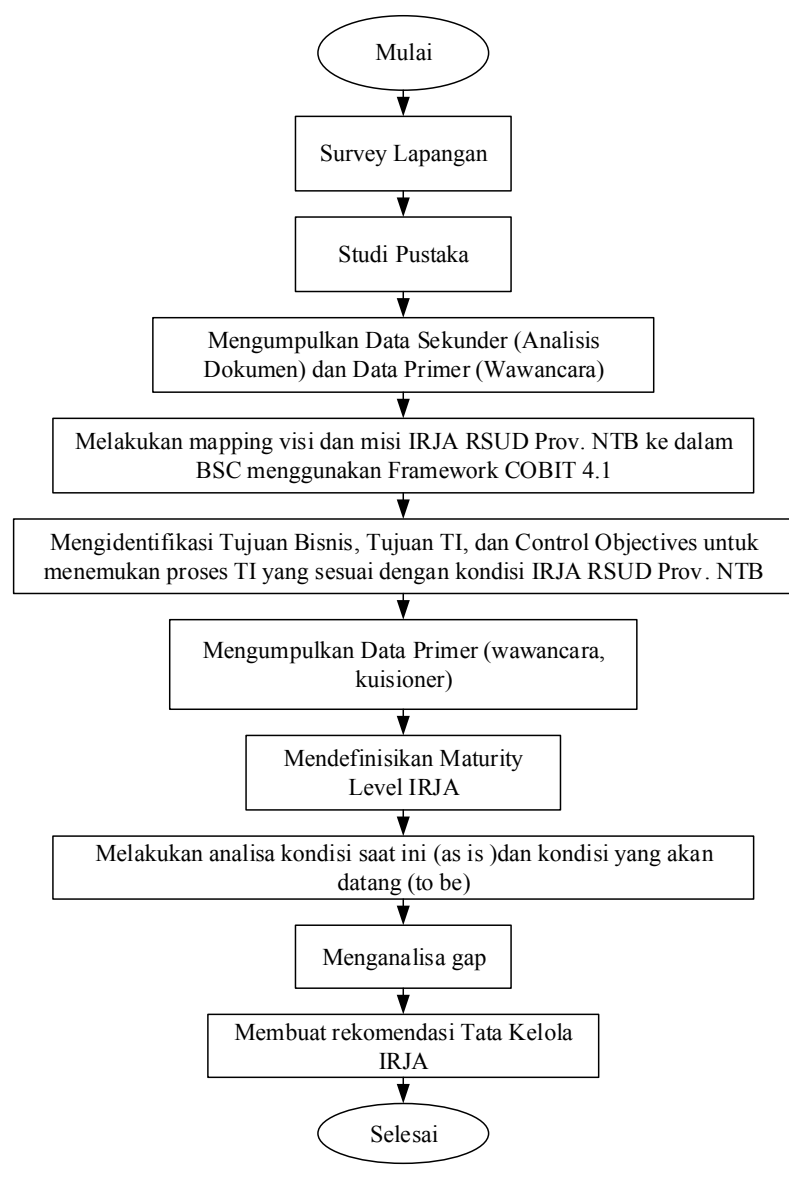

Gambar 1. Flowchart tahapan penelitian

\section{A. Survey Lapangan}

Pada tahap survei lapangan dilakukan pengumpulan permasalahan yang terjadi pada IRJA RSUD Prov. NTB seputar teknologi informasi yang telah diterapkan. Dari permasalahan tersebut, dapat diketahui permasalahan apa saja yang akan diperbaiki dengan tata kelola teknologi informasi.

\section{B. Studi Pustaka}

Setelah ditemukan permasalahan, lalu dilakukan studi pustaka dengan melihat literatur tata kelola TI yang terkait. Literatur yang digunakan adalah hasil penelitian sebelumnya, jurnal penerapan yang berhubungan dengan framework COBIT 4.1 dan buku pedoman COBIT 4.1.
C. Mengumpulkan data sekunder (analisis dokumen) dan data primer (wawancara)

Data diperoleh dari dokumen tertulis dari IRJA dan website resmi RSUD Prov. NTB. Data tersebut berupa pengumpulan data organisasi dalam hal ini IRJA RSUD Prov. NTB yang terdiri dari:

a. Visi dan misi IRJA RSUD Prov. NTB

b. Struktur organisasi IRJA

c. Dokumentasi alur pelayanan pada IRJA RSUD Prov. NTB

d. SOP Sistem Informasi Manajemen Rumah Sakit (SIMRS)

Pengumpulan data lainnya yaitu wawancara terhadap pihak terkait di IRJA, tujuannya adalah untuk mengetahui aplikasi apa saja yang digunakan dalam membantu proses pelayan pada IRJA RSUD Prov. NTB beserta kendalanya.

D. Melakukan mapping visi dan misi IRJA RSUD Prov. NTB ke dalam BSC dengan framework COBIT 4.1

Pada bagian ini, akan dijelaskan bagaimana pemetaan visi misi IRJA menjadi bagian balanced scorecard sesuai dengan framework COBIT 4.1. Balance Scorecard digunakan untuk sistem pengukuran kinerja, sehingga dapat membantu organisasi untuk merencanakan, memfokuskan, dan mengelola strateginya. Pada balance scorecard dilakukan pendekatan melalui 4 perspektif yaitu perspektif finansial, perspektif pelanggan, perspektif internal dan perspektif pembelajaran dan pertumbuhan.

\section{E. Mengidentifikasi tujuan bisnis, tujuan TI dan control objectives untuk menemukan proses TI yang sesuai dengan kondisi IRJA RSUD Prov. NTB}

Setelah dilakukan proses mapping menggunakan balance scorecard, kemudian ditentukan tujuan bisnis yang akan digunakan dalam perancangan tata kelola TI. Tujuan bisnis yang digunakan sesuai dengan framework COBIT 4.1. Tujuan bisnis yang terdapat pada framework COBIT 4.1 yaitu sebanyak 17 tujuan bisnis. Namun tidak semua tujuan bisnis digunakan, hanya tujuan bisnis yang sesuai dengan visi dan misi IRJA yang akan digunakan

Selanjutnya dilakukan identifikasi tujuan TI. Identifikasi tujuan TI merupakan proses yang dilakukan setelah menentukan balance scorecard dan menentukan tujuan bisnis. Tujuan TI yang digunakan sudah ditentukan dalam COBIT 4.1 yaitu berjumlah 28 tujuan TI

Setelah dilakukan identifikasi tujuan TI selanjutnya dilakukan adalah menentukan proses TI berdasarkan domain TI. Proses TI merupakan proses yang akan digunakan di dalam tata kelola TI. Proses TI tersebut akan dipilih berdasarkan tahapan yang dilakukan sebelumnya. Terdapat 34 Proses TI yang akan ditentukan sesuai dengan kebutuhan organisasi berdasarkan framework COBIT 4.1

\section{F. Mengumpulkan data primer (wawancara dan kuesioner)}

Wawancara dilakukan dengan tujuan untuk mengetahui proses dan tahapan yang dilakukan pada IRJA serta apa sajakah pengelolaan TI serta permasalahan TI yang terjadi pada IRJA RSUD Prov NTB. Proses wawancara dilakukan 
untuk memastikan jawaban yang diberikan oleh narasumber sesuai dengan jawaban pada kuesioner. Pertanyaan wawancara yang diberikan berdasarkan proses TI yang terpilih dan mengacu pada control objectives proses TI tersebut. Narasumber yang diwawancarai berdasarkan RACI roles pada proses TI yang terpilih yang ada pada framework COBIT 4.1. Data dalam wawancara dihitung menggunakan kategori Low, Middle dan High

Kuesioner adalah kumpulan pertanyaan yang yang sedianya akan dijawab oleh responden yang akan diteliti. Pertanyaan kuesioner dibuat berdasarkan proses TI yang telah terpilih. Pada tahap ini hasil rekap jawaban kuesioner dari seluruh responden akan dijadikan data. Untuk menentukan responden kuesioner dapat dilihat berdasarkan struktur organisasi IRJA dan disesuaikan dengan RACI Roles untuk proses TI yang terpilih di framework COBIT 4.1. Pembuatan kuesioner dilakukan untuk mengetahui keadaan perusahaan dalam bentuk maturity level.

\section{G. Mendefinisikan tingkat kematangan di IRJA}

Dalam mengidentifikasi tingkat kematangan yang pertama kali dilakukan adalah menghitung nilai kematangan pada kondisi as-is dan to-be. Pendefinisian ini dilakukan agar mengetahui tingkat kematangan yang dimiliki oleh suatu perusahaan atau organisasi.

\section{H. Melakukan Analisa as-is dan to-be}

Pada tahap ini dilakukan analisis kondisi as-is dan tobe akan diterangkan kondisi as-is dan to-be yang diinginkan dari kegiatan yang telah dilakukan. kondisi asis dan to-be dibagi menjadi 2 kriteria yang berbeda dan menghubungkannya dengan 6 atribut kematangan yang sesuai pada kuesioner.

\section{Menganalisa gap}

Dari Analisis tingkat kematangan as-is dan tingkat kematangan to-be ditemukan adanya kesenjangan tingkat kematangan (Gap Analisis). Pada tahap ini dilakukan analisis terhadap as-is dan tingkat kematangan to-be dengan melakukan perbandingan antara tingkat kematangan sebelum dan sesudah melakukan perancangan tata kelola TI sehingga dapat ditemukan peningkatan tingkat kematangan per-levelnya.

\section{J. Membuat rekomendasi tata kelola TI}

Rekomendasi perbaikan dilakukan sesuai dengan maturity level. Maturity level yang akan diperbaiki dilihat dari spider chart. Rekomendasi perbaikan dimulai dari level yang sesuai dengan kondisi as-is sampai ke level kondisi to-be dengan atribut kematangan. Rekomendasi perbaikan yang diberikan dilakukan secara bertahap setelah mengetahui bagaimana kondisi saat ini maupun kondisi yang diharapkan.

\section{HASIl DAN PEMBAHASAN}

\section{A. Hasil Kuesioner Proses IT Terpilih}

Setelah melakukan proses wawancara dan kuesioner maka selanjutnya akan direkap jawaban dari responden ke dalam tabel rekapitulasi yang dibagi menjadi 2 yaitu data pada keadaan saat ini dan keadaan yang diinginkan.

\section{B. Proses Perhitungan Hasil Kuesioner}

\section{B.1 Interquartile Range (IQR)}

Proses ini akan dilakukan setelah melakukan rekapitulasi hasil kuesioner. Representasi hasil nilai IQR dapat dilihat pada diagram boxplot pada Gambar 2 dan Gambar 3.

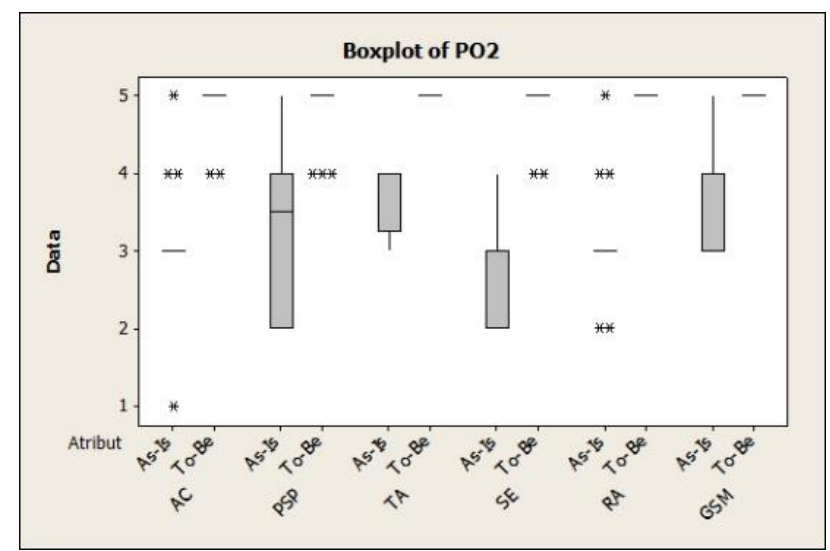

Gambar 2. Boxplot Proses TI PO2

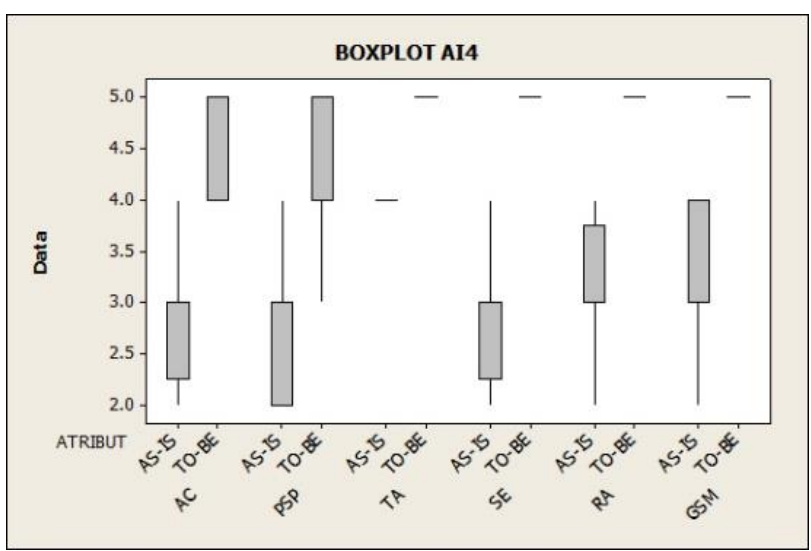

Gambar 3. Boxplot Proses TI AI4

\section{B.2. Uji Reliabilitas}

Pada Tabel I adalah hasil perhitungan uji realibilitas dengan metode Cronbach's Alpha dari kedua IT Proses yakni Proses PO2 dan Proses AI4.

TABLE I. HASIL UJI RELIABILITAS

\begin{tabular}{|c|c|c|c|}
\hline Proses TI & Status & Nilai & Reliabilitas \\
\hline \multirow{2}{*}{ PO2 } & As $/ s$ & 0.7627 & Reliabel \\
\cline { 2 - 4 } & To Be & 0.6038 & Reliabel \\
\hline \multirow{2}{*}{ Al4 } & As $/ s$ & 0.7550 & Reliabel \\
\cline { 2 - 4 } & To Be & 0.6140 & Reliabel \\
\hline
\end{tabular}

\section{B.3. Uji Validitas}

Pada Tabel II dan Tabel III merepresentasikan hasil perhitungan uji validitas menggunakan metode Korelasi Pearson dari kedua IT Proses yakni Proses PO2 dan AI4. 
TABLE II. Hasil Uji VALIDITAS PO2

\begin{tabular}{|c|c|c|c|c|}
\hline Atribut & Status & r-hitung & r-tabel(N=16) & Validitas \\
\hline \multirow{2}{*}{ AC } & As is & 0,614 & 0,497 & Valid \\
\cline { 2 - 5 } & To be & 0,749 & 0,497 & Valid \\
\hline \multirow{2}{*}{ PSP } & As is & 0,883 & 0,497 & Valid \\
\cline { 2 - 5 } & To be & 0,749 & 0,497 & Valid \\
\hline \multirow{2}{*}{ TA } & As is & 0,623 & 0,497 & Valid \\
\cline { 2 - 5 } & To be & 1 & 0,497 & Valid \\
\hline \multirow{2}{*}{ SE } & As is & 0,541 & 0,497 & Valid \\
\cline { 2 - 5 } & To be & 0,749 & 0,497 & Valid \\
\hline \multirow{2}{*}{ RA } & As is & 0,810 & 0,497 & Valid \\
\cline { 2 - 5 } & To be & 1 & 0,497 & Valid \\
\hline \multirow{2}{*}{ GSM } & As is & 0,597 & 0,497 & Valid \\
\cline { 2 - 5 } & To be & 1 & 0,497 & Valid \\
\hline
\end{tabular}

TABLE III. HASIL UjI VALIDITAS AI4

\begin{tabular}{|c|c|c|c|c|}
\hline Atribut & Status & r-hitung & r-tabel(N=16) & Validitas \\
\hline \multirow{2}{*}{$\mathrm{AC}$} & As is & 0,780 & 0,497 & Valid \\
\cline { 2 - 5 } & To Be & 0,698 & 0,497 & Valid \\
\hline \multirow{2}{*}{ PSP } & As is & 0,715 & 0,497 & Valid \\
\cline { 2 - 5 } & To Be & 0,918 & 0,497 & Valid \\
\hline \multirow{2}{*}{$\mathrm{TA}$} & As is & 1 & 0,497 & Valid \\
\cline { 2 - 5 } & To Be & 1 & 0,497 & Valid \\
\hline \multirow{2}{*}{$\mathrm{SE}$} & As is & 0,651 & 0,497 & Valid \\
\cline { 2 - 5 } & To Be & 1 & 0,497 & Valid \\
\hline \multirow{2}{*}{$\mathrm{RA}$} & As is & 0,720 & 0,497 & Valid \\
\cline { 2 - 5 } & To Be & 0,533 & 0,497 & Valid \\
\hline \multirow{2}{*}{$\mathrm{GSM}$} & As is & 0,700 & 0,497 & Valid \\
\cline { 2 - 5 } & To Be & 0,533 & 0,497 & Valid \\
\hline
\end{tabular}

\section{Mengidentifikasi Maturity Level}

Dari rekapitulasi jawaban responden yang ada, kemudian dapat dihitung maturity level di IRJA RSUD Prov. NTB dan dimasukan ke dalam Tabel IV untuk Maturity Level proses IT PO2 dan Tabel V untuk Maturity Level proses IT AI4.

TABLE IV. MATURITY LEVEL PO2

\begin{tabular}{|c|c|c|c|c|c|}
\hline \multirow{2}{*}{ No } & \multirow{2}{*}{ Atribut } & \multicolumn{2}{|c|}{ Nilai Kematangan } & \multicolumn{2}{c|}{ Tingkat Kematangan } \\
\cline { 3 - 6 } & & $\boldsymbol{A s}-\boldsymbol{I} \boldsymbol{s}$ & $\boldsymbol{T o}-\boldsymbol{B} \boldsymbol{e}$ & $\boldsymbol{A s}-\boldsymbol{I} \boldsymbol{~}$ & $\boldsymbol{T o}-\boldsymbol{B} \boldsymbol{e}$ \\
\hline 1 & AC & 3,12 & 4,87 & 3 & 4 \\
\hline 2 & PSP & 3,31 & 4,81 & 3 & 4 \\
\hline 3 & TA & 3,75 & 5 & 3 & 5 \\
\hline 4 & SE & 2,68 & 4,8 & 2 & 4 \\
\hline 5 & RA & 3,12 & 5 & 3 & 5 \\
\hline 6 & GSM & 3,68 & 5 & 3 & 5 \\
\hline
\end{tabular}

TABLE V. MATURITY LEVEL AI4

\begin{tabular}{|c|c|c|c|c|c|}
\hline \multirow{2}{*}{ No } & \multirow{2}{*}{ Atribut } & \multicolumn{2}{|c|}{ Nilai Kematangan } & \multicolumn{2}{|c|}{ Tingkat Kematangan } \\
\hline & & $A s-I s$ & To-Be & $A s-I s$ & To-Be \\
\hline 1 & $A C$ & 2,93 & 4,81 & 2 & 4 \\
\hline 2 & PSP & 2,75 & 4,56 & 2 & 4 \\
\hline 3 & TA & 4 & 5 & 4 & 5 \\
\hline 4 & SE & 2,93 & 5 & 2 & 5 \\
\hline 5 & RA & 3,18 & 4,93 & 3 & 4 \\
\hline 6 & GSM & 2.7 & 2 & 4.2 & 4 \\
\hline
\end{tabular}

Tingkat kematangan atau maturity level dari setiap proses yang dilakukan direpresentasikan menggunakan grafik. Berikut adalah Spider Chart kedua proses TI PO2 dan AI4 secara berturut-turut yakni pada Gambar 4 dan Gambar 5.

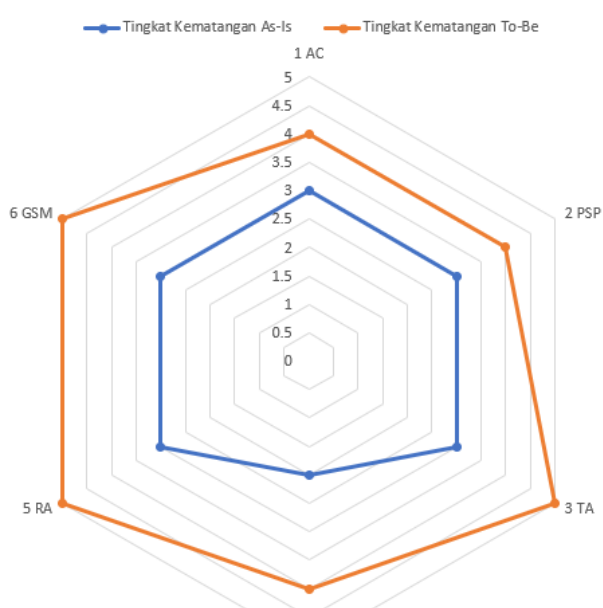

Gambar 4. Spider Chart Proses TI PO2

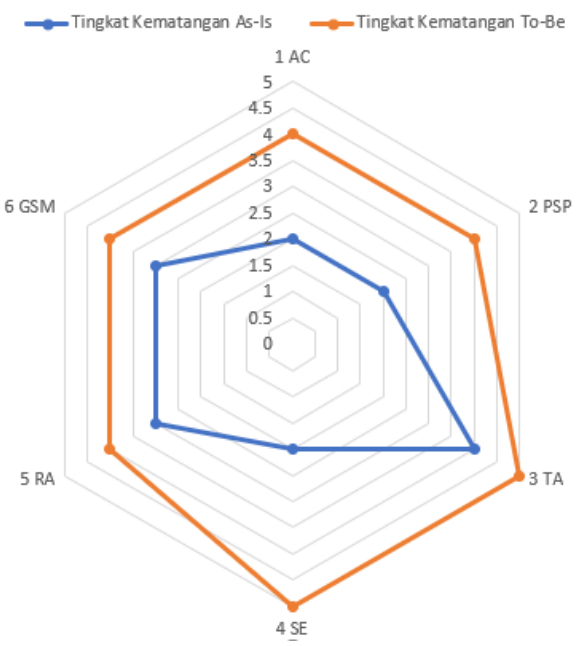

Gambar 5. Spider Chart Proses TI AI4

\section{C.1. Analisis Kondisi Saat Ini pada Proses IT PO2}

Pada atribut AC untuk maturity level kondisi saat ini berada pada level 3, berarti pada saat ini manajamen sudah memilki kepedulian dan kesadaran terhadap pentingnya arsitektur informasi, dimana pada level ini manajemen sudah mulai lebih formal dan terstruktur mengkomunikasikan mengenai pendefinisian penggunaan sistem yang sesuai dalam hal ini penggunaan SIRS pada IRJA. Selanjutnya pada level ini manajemen sudah sadar mengenai pengintegrasian sistem informasi dalam hal ini sudah terintegrasinya modul-modul SIRS yaitu modul pendaftaran, kasir \& poliklinik.

Pada atribut PSP untuk maturity level kondisi as-is berada pada level 3, berarti pada saat ini IRJA RSUD Prov. NTB sudah mengetahui prosedur tentang pengamanan data perusahaan dalam memantau saluran terhadap kepunyaan data dan informasi yang ada pada sistem informasi yang digunakan yaitu SIRS seperti kontrol terhadap akses sistem informasi yang digunakan, kontrol akses terhadap informasi. Namun pada saat ini di IRJA belum terdapat prosedur tertulis seperti prosedur 
permohonan untuk dapat mengakses aplikasi, prosedur permohonan akun untuk staf atau karyawan baru, prosedur untuk staf agar dapat melakukan akses data atau file tertentu.

Pada atribut TA untuk maturity level kondisi as-is berada pada level 3, berarti pada saat ini penggunaan alat teknologi informasi infomasi pada IRJA RSUD Prov. NTB sudah diterapkan namun belum sepenuhnya terintegrasi, seperti penggunaan desktop standar yang didalamnya terdapat sistem informasi rumah sakit yag terdiri dari berbagai modul yang digunakan seperti modul kasir, pendaftaran dan modul poliklinik. Namun dalam penerepannya masih kurang maksimal hal ini dibuktikan dengan belum terintegrasinya nomor antrian yang ada di mainhall rumah sakit dengan nomor antrian yang ada di setiap poli rawat jalan yang akan dituju.

Pada atribut SE untuk maturity level kondisi as-is berada pada level 2, berarti pada saat ini IRJA RSUD Prov. NTB dalam mengembangkan keterampilan dan keahlian SDM dalam bentuk pelatihan dalam menggunakan alat teknologi informasi dan pengoperasian sistem informasi masih dilakukan secara informal dimana pelatihan diberikan hanya sekali oleh bagian IT RSUD Prov. NTB yaitu unit SIRS ,secara langsung kepada tiap-tiap petugas unit yang bertugas menggunakan sistem.

Pada atribut RA untuk maturity level kondisi as-is berada pada level 3, berarti pada saat ini IRJA RSUD Prov. NTB telah mendefinisikan dan menentukan pembagian tugas kepada orang yang diberikan tanggung jawab dalam penggunaan sistem informasi yang ada. Seperti dalam penggunaan modul kasir pada IRJA dilakukan oleh petugas billing, dan penggunaan modul poliklinik dilakukan oleh petugas poli untuk menginputkan tindakan yang ada di poli.

Pada atribut GSM untuk maturity level kondisi saat ini berada pada level 3, berarti pada saat ini IRJA RSUD Prov. NTB telah melakukan pengawasan dan pengukuran kinerja terhadap penggunaan sistem informasi yang ada yaitu SIRS, namun masih belum dikomunikasikan secara menyeluruh. Evaluasi atau penilaian kinerja saat ini yang dilakukan oleh kepala IRJA masih dilakukan secara informal hanya melihat secara langsung apakah petugas yang memiliki tugas menjalankan modul sistem informasi sudah sesuai dengan tugas dan tanggung jawabnya.

\section{C.2. Analisis Kondisi yang Diinginkan pada Proses IT PO2}

Pada atribut AC untuk maturity level kondisi yang diharapkan yaitu pada level 4, yaitu dengan meningkatkan tingkat kesadaran manajamen akan pentingnya arsitektur informasi didukung dengan teknik komunikasi formal yang baik antar manajemen. Dimana IRJA diharapkan sudah melakukan pertemuan yang rutin atau sosialisasi dengan bagian IT RSUD Prov. NTB yaitu bagian instalasi SIRS untuk mengkomunikasikan mengenai pendefinisian penggunaan sistem yang sesuai dalam hal ini penggunaan SIRS pada IRJA.

Pada atribut PSP untuk maturity level kondisi yang diharapkan yaitu pada level 4, yaitu IRJA RSUD Prov. NTB memiliki prosedur tentang pengamanan data perusahaan dalam melakukan akses terhadap siapakah pemilik data dan informasi yang ada pada sistem informasi yang digunakan yaitu SIRS seperti prosedur permohonan izin akses sistem informasi yang digunakan, prosedur penambahan akun untuk petugas baru, dan prosedur akses data atau file tertentu.

Pada atribut TA untuk maturity level kondisi yang diharapkan yaitu pada level 5, yaitu memastikan penggunaan alat teknologi seperti penggunaan desktop standar dan penggunaan sistem informasi manajemen rumah sakit di IRJA RSUD Prov. NTB sudah distandarisasi dan digunakan secara menyeluruh serta saling terintegrasi.

Pada atribut SE untuk maturity level kondisi yang diharapkan yaitu pada level 4, yaitu dalam mengembangkan keahlian SDM dalam penggunaan alat teknologi seperti penggunaan desktop standar dan sistem informasi manajemen rumah sakit dalam bentuk pelatihan terhadap petugas IRJA yang menggunakan alat teknologi serta mengoperasikan modul yang ada pada SIRS sudah dilakukan secara formal dan terjadwal.

Pada atribut RA untuk maturity level kondisi yang diharapkan yaitu pada level 5, yaitu pada level ini sudah didefinisikan tugas dan tanggung jawab petugas TI dengan jelas dimana penentuan tanggung jawab dilakukan oleh kepala IRJA kepada orang yang bertanggung jawab dalam mengelola sistem informasi manajemen rumah sakit yaitu petugas IRJA yang menjalankan modul-modul dalam SIMRS.

Pada atribut GSM untuk maturity level kondisi yang diharapkan yaitu pada level 5, Unit IT RSUD Prov. NTB yaitu unit instalasi SIRS melakukan pengawasan secara berkala dan secara menyeluruh terhadap penggunaan sistem informasi pada di IRJA dan evaluasi dilakukan secara formal dan memiliki prosedur yang telah ditetapkan oleh bagian SIRS, seperti prosedur untuk pemantauan penggunaan modul SIRS.

\section{C.3. Analisis Kondisi Saat Ini pada Proses IT AI4}

Pada atribut AC untuk maturity level kondisi as-is berada pada level 2, berarti pada saat ini IRJA RSUD Prov. NTB sudah memilki kesadaran dalam mendokumentasikan prosedur penggunaan dan pengoperasian sistem informasi manajemen rumah sakit, seperti prosedur akses aplikasi, database pada SIMRS, backup aplikasi, prosedur penggunaan komputer, dan prosedur penggunaan modul-modul pendaftaran, poliklinik, kasir pada SIRS. Namun saat ini IRJA belum memiliki prosedur tertulis. Hal ini dibuktikan pada saat ini di IRJA belum diberikan prosedur penggunaan SIRS oleh bagian IT rumah sakit yaitu unit instalasi SIRS.

Pada atribut PSP untuk maturity level kondisi as-is berada pada level 2, berarti pada saat ini IRJA RSUD Prov. NTB sudah melakukan penerapan dalam mendokumentasikan prosedur penggunaan dan pengoperasian sistem informasi yang digunakan namun prosedur yang digunakan tidak terdokumentasi. Pada saat ini di IRJA prosedur diberikan secara lisan oleh unit 
instalasi SIRS kepada petugas yang menggunakan sistem di IRJA.

Pada atribut TA untuk maturity level kondisi as-is berada pada level 4, berarti pada saat ini IRJA RSUD Prov. NTB penggunaan prosedur perangkat teknologi informasi seperti penggunaan desktop standar, sudah ada beberapa yang terintegrasi dangan alat-alat terkait lainnya, namun belum secara menyeluruh.

Pada atribut SE untuk maturity level kondisi as-is berada pada level 2, berarti pada saat ini di IRJA RSUD Prov. NTB rencana pelatihan untuk penggunaan dan pengoperasian sistem informasi manajemen rumah sakit masih diberikan secara informal oleh unit instalasi SIRS hanya dalam rangka memenuhi kebutuhan bukan atas dasar rencana yang disepakati

Pada atribut RA untuk maturity level kondisi as-is berada pada level 3, berarti penentuan siapa yang mempunyai tanggung jawab terhadap data serta kepemilikannya dalam dokumentasi, petunjuk penggunaan operasi dan materi pelatihan dalam penggunaan dan pengoperasian sistem informasi di IRJA RSUD Prov. NTB telah didefinisikan dan orang yang bertanggung jawab telah ditentukan yaitu unit instalasi SIRS.

Pada atribut GSM untuk maturity level kondisi as-is berada pada level 3, berarti pada saat ini unit instalasi SIRS Prov. NTB telah melakukan pengawasan dan evaluasi dalam dokumentasi yang ditujukan untuk pengguna, petunjuk penggunaan dan cara operasional dan materi pelatihan terhadap penggunaan sistem informasi manajemen rumah sakit namun belum dikomunikasikan menyeluruh kebagian IRJA.

\section{C.4. Analisis Kondisi yang Diinginkan pada Proses IT AI4}

Pada atribut AC untuk maturity level kondisi yang diharapkan yaitu pada level 4, yaitu dengan meningkatkan kesadaran dan komunikasi manajemen IRJA dan pihak SIRS dalam dokumentasi yang ditujukan untuk pengguna, petunjuk penggunaan dan cara operasional dan materi pelatihan penggunaan dan pengoperasian sistem informasi manajemen rumah sakit pada RSUD Prov. NTB. Yaitu dengan adanya dokumentasi dan petunjuk yang terstandarisasi yang akan digunakan oleh petugas yang menjalankan SIMRS pada IRJA, serta diadakannya sosialisasi maupun pertemuan berkala mengenai hal tersebut

Pada atribut PSP untuk maturity level kondisi yang diharapkan yaitu pada level 4, yaitu memastikan seluruh aspek dalam penerapan pendokumentasi pengguna, manual operasi, dan materi pelatihan penggunaan dan pengoperasian sistem informasi manajemen rumah sakit yang digunakan pada RSUD Prov. NTB sudah terdokmentasi dengan baik. Yaitu dengan diterapkannya dokumentasi dan petunjuk yang terstandarisasi yang akan digunakan oleh petugas yang menjalankan SIMRS pada IRJA, serta diadakannannya training untuk menjamin sistem informasi yang dijalankan secara tepat

Pada atribut TA untuk maturity level kondisi yang diharapkan yaitu pada level 5, yaitu memastikan pendokumentasian pengguna, manual operasi dan materi pelatihan suatu sistem informasi manajemen rumah sakit dan penggunaan alat teknologi seperti penggunaan desktop standar dalam yang digunakan pada RSUD Prov. NTB sudah menjadi praktik terbaik yang diikuti dan diotamatisasi

Pada atribut SE untuk maturity level kondisi yang diharapkan yaitu pada level 5, yaitu manajemen IRJA dibantu pihak SIRS memastikan kebutuhan tersedianya sumber daya pada bidang TI untuk mendukung dokumentasi yang ditujukan untuk pengguna, petunjuk penggunaan dan cara operasional dan materi pelatihan penggunaan dan pengoperasian SIMRS telah diupdate secara rutin, sesuai dengan pembaharuan sistem maupun perangkat yang ada

Pada atribut RA untuk maturity level kondisi yang diharapkan yaitu pada level 4, yaitu memastikan penetapan siapakah yang bertanggung jawab dan kepemilikan dalam dokumentasi yang ditujukan untuk pengguna, petunjuk penggunaan dan cara operasional dan materi pelatihan telah sepenuhnya dijalankan oleh masing-masing individu atau petugas yang menggunakan modul-modul SIRS pada IRJA

Pada atribut GSM untuk maturity level kondisi yang diharapkan yaitu pada level 4, yaitu dilakukannya penetapan peran dan tanggung jawab kepada SDM (staff TI di IRJA) yang memiliki peran dalam pengawasan terhadap kinerja manajemen dalam menggunakan SI dan dilakukannya evaluasi terhadap hasil dari pengawasan tersebut, dalam hal ini dilakukan oleh pihak manajemen IRJA dan dibantu oleh unit SIRS

\section{C.5. Analisis Gap}

Peningkatan kematangan merupakan proses perbaikan dan pembelajaran yang berkelanjutan. Proses ini dilakukan secara bertahap agar peningkatan proses tersebut lebih efektif.

Keseragaman nilai kematangan dapat diperoleh dengan menaikkan nilai kematangan atribut SE yang berada pada proses PO2. Sedangkan pada AI4 terdapat atribut AC, PSP, SE yang akan dinaikkan menjadi level 3. Setelah semua atribut mencapai kematangan 3 , proses pematangan atribut harus dilakukan bersamasama sehingga semua atribut pada proses PO2 maupun AI4 berada pada tingkat kematangan yang sama, yaitu tingkat kematangan 4. Setelah semua mencapai nilai kematangan 4 maka akan dilanjutkan dengan pencapaian nilai kematangan 5 sesuai yang diharapkan.

\section{Rekomendasi Perbaikan}

Seperti yang dijelaskan sebelumnya, rekomendasi tindakan perbaikan dibagi menjadi 3 bagian agar proses peningkatan kematangan dapat berjalan dengan efektif.

\section{D.1. Pencapaian Maturity Level 3}

Beberapa tindakan yang perlu dilakukan agar nilai kematangan yang berada pada tingkat kematangan 2 mencapai tingkat kematangan 3 pada proses IT PO2, yaitu: 
- Pada atribut SE, melakukan pelatihan formal oleh unit SIRS mengenai SIM RS kepada petugas TI yang menjalankan modul-modul sistem informasi manajemen rumah sakit pada IRJA, melakukan pelatihan formal secara berkala oleh unit SIRS kepada petugas TI di IRJA yang menjalankan modul-modul SIM RS.

- Beberapa tindakan yang perlu dilakukan agar nilai kematangan yang berada pada tingkat kematangan 2 mencapai tingkat kematangan 3 pada proses IT AI4, yaitu:

- Pada atribut AC, melakukan sosialisasi kepada petugas TI yang ada pada IRJA mengenai hal-hal yang berkaitan dengan pendokumentasian prosedur penggunaan dan pengoperasian SIM RS seperti prosedur akses modul pada sistem, backup data, prosedur penggunaan komputer. Dengan sosialisasi, diharapkan tidak terjadinya adanya salah pengertian di kalangan petugas TI pada IRJA terkait penggunaan prosedur tersebut, memastikan bahwa proses pengunaan dan pengoperasian sistem informasi manajemen rumah sakit, prosedurnya terdokumentasi, dan dikomunikasikan.

- Pada atribut PSP, memastikan bahwa manajemen IRJA dan petugas TI yang ada pada IRJA memiliki prosedur tertulis tentang prosedur penggunaan dan pengoperasian sistem informasi manajemen rumah sakit seperti prosedur akses modul pada sistem, backup data, prosedur penggunaan komputer, melakukan update prosedur yang ada oleh unit SIRS, jika ada pembaharuan sistem informasi atau perangkat yang digunakan

- Pada atribut SE, melakukan pelatihan formal oleh unit SIRS mengenai SIM RS kepada petugas TI yang menjalankan modul-modul SIM RS pada IRJA.

\section{D.2. Pencapaian Maturity Level 4}

Pada proses dibawah ini adalah bentuk rekomendasi yang dilakukan agar nilai kematangan yang berada pada tingkat kematangan 3 mencapai tingkat kematangan 4 pada proses IT PO2, yaitu:

- Pada atribut AC, Memastikan pengembangan arsitektur informasi dengan melakukan pemantauan secara berkala seperti rapat kerja, sosialisasi dan sebagainya yang dilakukan oleh pihak SIRS terhadap IRJA, Melaksanakan rutinitas untuk mensosialisasikan dan mengkomunikasikan antar individu di perusahaan secara terjadwal dan berkesinambungan.

- Pada atribut PSP, Melakukan arahan kepada seluruh petugas TI pada IRJA untuk selalu memastikan aktivitas dan kegiatan mereka terkait penggunaan sistem informasi agar sesuai dengan best practices.

- Pada atribut TA, Memastikan bahwa penggunaan alat bantu dalam menggunakan SIRS yaitu desktop standar sudah terintergasi antar unit di IRJA. Memastikan bahwa penggunaan modul-modul dalam sistem informasi manajemen rumah sakit oleh petugas IRJA sesuai dengan prosedur yang ada.

- Pada atribut SE, Merencanakan pelatihan pengembangan SDM yang ada pada IRJA untuk mendukung kebijakan penerapan arsitektur informasi sesuai standar yang telah ditetapkan.
- Pada atribut RA, Mendefinisikan tugas pokok dan fungsi masing-masing petugas TI dengan jelas, demikian pula dengan tugas dan tanggung jawab dalam sub bagian. - Pada atribut GSM, Menetapkan dan menyelaraskan tujuan terkait penggunaan sistem informasi manajemen rumah sakit sesuai dengan tujuan bisnis perusahaan. Membuat penyusunan rencana pengembangan dan pengintegrasian seluruh kegiatan pelayanan di IRJA yang menggunakan SIM RS yang belum terintegrasi.

Pada proses di bawah ini adalah bentuk rekomendasi yang dilakukan agar nilai kematangan yang berada pada tingkat kematangan 3 mencapai tingkat kematangan 4 pada proses IT AI4, yaitu:

- Pada atribut AC, meningkatkan sosialisasi mengenai kebutuhan untuk pendokumentasian prosedur penggunaan dan pengoperasian SIM RS.

- Pada atribut PSP, memformalkan segala pendokumentasian prosedur penggunaan dan pengoperasian SIM RS ke dalam dokumen rencana maupun SOP yang baku. Memastikan seluruh aspek dalam proses pendokumentasian prosedur penggunaan dan pengoperasian SIM RS informasi harus dipastikan dan terdokumentasi dengan baik

- Pada atribut SE, menjalankan pelatihan formal prosedur penggunaan dan pengoperasian SIM RS dengan personel TI yang terkait. Menerapkan mekanisme knowledge sharing diantara personel TI terkait, untuk memberikan kesempatan kepada antar personil terkait berbagi pengetahuan yang mereka miliki antar personil.

- Pada atribut RA, Manajemen IRJA memastikan untuk memberikan kapasitas dan responsibilitas terhadap sumber daya TI yang sesuai dengan keahlian terkait TI.

- Pada atribut GSM, membuat aturan yang dapat memberikan kapasitas dan responsibilitas kepada staf yang sesuai dengan kapasitasnya di bidang TI dalam pengawasan terhadap kinerja manajemen dalam menggunakan sistem informasi.

\section{D.3. Pencapaian Maturity Level 5}

Proses yang dilakukan agar nilai kematangan yang berada pada tingkat kematangan 4 mencapai tingkat kematangan 5 pada proses IT PO2, yaitu:

- Pada atribut TA, membuat penyusunan rencana kebutuhan peralatan dan prasarana yang mendukung jalannya penggunaan sistem informasi manajemen rumah sakit sesuai kebutuhan dan rencana pengembangan. Memperbaharui secara periodik dan berkelanjutan desktop standar yang digunakan dalam mendukung penggunaan sistem informasi manajemen rumah sakit.

- Pada atribut RA, Menetapkan dan memonitor tugas pokok dan fungsi masing-masing petugas TI dengan jelas, demikian pula dengan tugas dan tanggung jawab dalam sub bagian. Meningkatkan dan memonitor SOP agar dapat mencakup lebih banyak aspek dan memiliki keselarasan antar sub bagian.

- Pada atribut GSM, Memastikan tujuan terkait penggunaan sistem informasi manajemen rumah sakit 
sesuai dengan tujuan bisnis perusahaan dan mencapai praktik terbaik. Melakukan monev dan penyusunan hasil analisa pelaksanaan oleh unit SIRS terhadap pencapaian penggunaan sistem informasi yang ada kepada petugas TI yang menggunakan sistem informasi manajemen rumah sakit di IRJA secara berkala dan berkesinambungan. Melakukan monev hasil kegiatan pelayanan yang terintegrasi dalam sistem informasi manajemen rumah sakit.

Beberapa proses yang dilakukan agar nilai kematangan yang berada pada tingkat kematangan 4 mencapai tingkat kematangan 5 pada proses IT AI4, yaitu:

- Pada atribut TA, Memastikan proses dokumentasi pengoperasian dan penggunaan terus dilakukan peningkatan melalui alat atau metode dengan penerapan yang baru. Memastikan cara pendokumentasian dan materi pelatihan diperbaharui agar terlihat perubahan organisasi, operasional dan perangkat lunak

- Pada atribut SE, Memastikan kebutuhan keahlian SDM bidang TI secara rutin telah terupdate untuk seluruh proses pada IRJA terkait pendokumentasian penggunaan dan pengoperasian sistem informasi manajemen rumah sakit. Memastikan pelatihan terkait terkait pendokumentasian penggunaan dan pengoperasian SIRS telah dilakukan sesuai prosedur dan rencana yang telah didefinisikan sebelumnya. Memastikan penerapan mekanisme knowledge sharing diantara personel terkait berjalan sesuai dengan rencana. Dilakukan pemetaan dan pembinaan staf IRJA dengan performance yang kurang memuaskan dalam mengoperasikan sistem informasi manajemen rumah sakit.

\section{D.4 Rencana Aksi}

Rencanan aksi diperlukan untuk mencapai tujuan yang dikembangkan oleh Rumah Sakit Prov. NTB. Rencana aksi yang dapat dilakukan adalah sebagai berikut :

1. Mengoptimalkan penggunaan SIM RS pada IRJA RSUD Prov. NTB, dengan cara:

a. Menyusun rencana pengembangan dan pemeliharaan infrastruktur teknologi yang mendukung penggunaan SIM RS RSUD Prov. NTB dimana komponen-komponen infrastruktur pendukung TI seperti platform hardware, information system, software, networking, dan Internet.

b. Melihat seberapa besar frekuensi error terhadap pengunaan dan pengoperasian dalam menjalankan SIM RS

c. Melakukan pengembangan dan pengintegrasian seluruh kegiatan pelayanan yang ada di IRJA yang belum terintegrasi dengan SIM RS .

d. Melakukan pembinaan dan pengembangan terhadap petugas yang menggunakan SIM RS.

2. Membuat integrasi SIM RS, sehingga dapat mencapai tujuan RSUD Prov. NTB, dengan cara:

a. Menetapkan kepemilikan data dalam penggunaan SIM RS, dan juga menjamin integritas data yang ada pada SIM RS. b. Melakukan update dari model data enterprise secara menyeluruh dan berkesinambungan.

c. Meningkatkan aktivitas validasi data.

d. Melakukan pengintegrasian modul pendaftaran SIM RS pada mainhall RSUD Prov. NTB terhadap modul pendaftaran yang ada di IRJA

3. Memastikan penggunaan yang tepat dari pengunaan SIM RS pada IRJA RSUD Prov. NTB dengan cara:

a. Mengkomunikasikan dan melatih user SIM RS yaitu pada manajemen bisnis, staf pendukung dan staf operasional

b. Membuat dokumen panduan kewajiban dan responsibiltas, yang merupakan dokumen yang berisi detail fungsi, tugas dan tanggung jawab setiap individu yang berada dalam struktur organisasi IRJA yang menjalankan modul SIM RS IRJA RSUD Prov. NTB

c. Memastikan adanya ketersediaan, keutuhan dan akurasi dari penggunaan dan dokumentasi operasional SIM RS.

4. Memastikan kepuasan petugas IRJA yang menjalankan modul-modul dari pengunaan SIM RS terhadap tingkat pelayanan yang diberikan di IRJA RSUD Prov. NTB dilakukan dengan cara monev dan melakukan penyusunan analisa hasil pelaksanaan/capaian dalam penggunaan sistem untuk mendukung kegiatan pelayanan.

5. Memastikan kepuasan manajemen di IRJA RSUD Prov. NTB terhadap penggunaan prosedur penggunaan dan pengoperasian SIM RS dan pelatihan terkait dengan cara:

a. Melakukan monev seluruh SPO pengoperasian sistem secara berkala dan berkesinambungan

b. Mengukur, memantau, dan memonitor kinerja teknologi informasi berdasarkan standar kualitas yang telah ditentukan, sebagai parameter tercapai atau tidaknya sasaran organisasi

c. Memantau dan melaporkan tingkat kinerja layanan teknologi informasi dari waktu ke waktu secara periodik

6. Membuat dokumentasi lengkap dan prosedur dalam penggunaan SIM RS.

a. Mengembangkan dan menyediakan dokumentasi dari transfer pengetahuan terhadap penggunaan SIM RS.

b. Membuat bahan pelatihan

c. Menyusun dokumen panduan teknik pengoperasian SIM RS yang diperuntukkan oleh staf yang ada pada IRJA RSUD Prov. NTB yang telah ditetapkan sebagai penanggung jawab dalam menjalankan modul yang ada pada sistem

d. Meningkatkan kehadiran pengguna dan operator dari masing-masing pelatihan aplikasi

e. Mengurangi jangka waktu antara perubahan /update dari pelatihan, prosedur dan dokumentasi

f. Menjalankan dan memelihara prosedur keamanan sistem informasi manajemen rumah sakit 


\section{KESIMPULAN DAN SARAN}

\section{A. Kesimpulan}

1. Langkah-langkah untuk mendapatkan rekomendasi tata kelola teknologi informasi di IRJA RSUD Prov. NTB telah disusun dengan mengacu kepada visi dan misi yang ada di IRJA yang bertujuan untuk meningkatkan tata kelola teknologi informasi yang ada saat ini menuju tingkat kematangan yang diharapkan yaitu dengan melakukan studi pustaka, mengidentifikasi masalah, mengidentifikasi Balanced Scorecard, mengidentifikasi Business Goals, IT Goals dan IT Process, melakukan wawancara dan kuesioner lalu menghitung hasil kuesioner dengan melakukan uji realibilitas dan validitas serta menghitung maturity level sebagai acuan dalam memberikan rekomendasi perbaikan.

2. Dalam proses tata kelola teknologi informasi di IRJA RSUD Prov. NTB sudah memiliki kesadaran dalam penerapan teknologinya, tepatnya rata-rata atribut proses IT yang terpilih yaitu PO2 (Define the Information Architecture) dan proses AI4 (Enable operation and use) berada pada tingkat kematangan 3 (defined process). Hal ini berarti kondisi dimana perusahan telah memiliki prosedur standar formal, namun belum secara tertulis, telah dikerjakan dalam aktivitas sehari-hari dan tidak adanya pengawasan untuk menjalankan prosedur, sehingga memungkinkan terjadinya banyak penyimpangan.

3. Atribut pada proses $\mathrm{PO} 2$ dan AI4 rata-rata kondisi yang diharapkan berada pada tingkat kematangan 5 (optimised). Atribut yang berada pada tingkat kematangan 5 berarti bahwa kondisi dimana perusahaan dianggap telah mengimplementasikan tata kelola manajemen teknologi informasi yang mengacu pada praktik terbaik. Proses telah mencapai level terbaik karna perbaikan yang terus menerus sehingga dapat menambah efiensi dan kinerja proses, dan memudahkan perusahaan untuk beradaptasi terhadap perubahan.

B. Saran

1. Penelitian selanjutnya dapat menggunanakan framework tata kelola IT lain untuk proses audit tata kelola teknologi informasi di IRJA RSUD Prov. NTB

2. Disarankan untuk penelitian selanjutnya agar mengusahakan data kuesioner dapat ditambah jumlah respoden dari masing-masing unit kerja sehingga data yang dihasilkan lebih valid dan nilai kemampuan tata kelola teknologi informasi di IRJA RSUD Prov. NTB dapat disimpulkan dengan lebih baik.

3. Agar hasil tata kelola dapat lebih maksimal, diharapkan pihak IRJA RSUD Prov. NTB dapat memadukan hasil penelitian serupa pada proses IT yang lain, sehingga pelaksanaannya dapat lebih terintegrasi dan mendapatkan hasil yang maksimal.

\section{DAFTAR PUSTAKA}

[1] N. Agitha, Perancangan Tata Kelola Teknologi Informasi Berbasis Cobit (Studi Kasus Sumber Daya Manusia Kesehatan Dinas Kesehatan Provinsi NTB). MMT ITS, 2012.

[2] D. Ramadhanty, "Penerapan Tata Kelola Teknologi Informasi dengan Menggunakan COBIT Framework," Eksplora Inf., vol. 4 no. 2, 2015.

[3] B. B. Wahono, "PERANCANGAN TATAKELOLA TEKNOLOGI INFORMASI UNTUK PENINGKATAN LAYANAN SISTEM INFORMASI KESEHATAN (STUDI KASUS DINAS KESEHATAN KABUPATEN JEPARA)," Simetris J. Tek. Mesin, Elektro dan Ilmu Komput., 2015.

[4] B. N. Revinggar, H. Tanuwijaya, and I. A. Mastan, "Audit Sistem Informasi Instalasi Rawat Jalan Berdasarkan Perspektif Pelanggan Balanced Scorecard Dan Standar Cobit 4.1 (Studi Kasus: Rumah Sakit Umum Haji Surabaya)," J. JSIKA, 2012.

[5] I. R. Yunus, "ANALISIS TATA KELOLA TEKNOLOGI INFORMASI PADA LAYANAN INFRASTRUKTUR JARINGAN RSUD PROVINSI NTB MENGGUNAKAN COBIT 4.1," JTIKA, vol. Vol. 1, no. No. 1, pp. 19-30, 2019.

[6] ITGI, Framework Control Objectives Management Guidelines Maturity Models. 2007.

[7] K. Surendro, Implementasi Tata Kelola Teknologi Informasi. Bandung: Informatika, 2009.

[8] S. Rohman, N. Agitha, and R. Afwani, "ANALISA TATA KELOLA TIEKNOLOGI INFORMASI UNTUK MENINGKATKAN DESTINASI PARIWISATA DI LOMBOK (STUDI KASUS DI DINAS PARIWISATA PROV. NTB) MENGGUNAKAN FRAMEWORK COBIT 5," J. Teknol. Informasi, Komputer, dan Apl. (JTIKA ), 2020.

[9] N. Rabbani, "ANALISIS TATA KELOLA TEKNOLOGI INFORMASI UNTUK MENDEFINISIKAN PROSES TI PADA STIE 45 MATARAM DENGAN MENGGUNAKAN FRAMEWORK COBIT 4.1," JTIKA, vol. 1, no. No. 1, pp. 65-76, 2019.

[10] N. Agitha, Buku Ajar Tata Kelola Teknologi Informasi. 2017.

[11] S. Manikandan, "Measures of dispersion," Journal of Pharmacology and Pharmacotherapeutics. 2011.

[12] I. P. Rahayu and N. Agitha, "Analisis Tata Kelola Teknologi Informasi Menggunakan Kerangka Kerja COBIT 5 (studi Kasus : DISKOMINFO Lombok Barat)," J. Teknol. Informasi, Komputer, dan Apl. (JTIKA ), vol. 1, no. 2, pp. 131-140, 2019.

[13] G. M. Basil, N. Agitha, and M. A. Albar, "Analisis Tata Kelola Teknologi Informasi Untuk Meningkatkan Mutu Sumber Daya Manusia Menggunakan Framework COBIT 5 (Studi Kasus: Politeknik Pariwisata Negeri Lombok)," $J$. Teknol. Informasi, Komputer, dan Apl. (JTIKA ), 2019. 